\title{
An unusual cause of acute abdomen: wandering spleen with infarction
}

\author{
Fred Bernardes Filho 1,2 \\ Rogério Nastri Filho \\ Rodrigo Teixeira Vena ${ }^{3}$ \\ Eduardo Miguel Febrônio ${ }^{3}$ \\ iD Rodolfo Mendes Queiroz ${ }^{3}$
}

\begin{abstract}
1. Emergency Department, Hospital Imaculada Conceição da Sociedade Portuguesa de Beneficência, Ribeirão Preto, SP, Brasil 2. Dermatology Division, Department of Medical Clinics, Ribeirão Preto Medical School, University of São Paulo, Ribeirão Preto, SP, Brasil 3. Department of Radiology and Imaging, DOCUMENTA, Centro Avançado de Diagnóstico por Imagem, Hospital São Francisco, Ribeirão Preto, SP, Brasil
\end{abstract}

\section{CASE}

An 18-year-old woman presented with 7-day history of fever and left lower quadrant abdominal pain. She had past history of Hirschsprung's disease operated on childhood. Positive findings on physical examination included marked lower abdominal tenderness mainly over the left flank and left iliac fossa. Laboratory testing was remarkable for elevated white blood cells at $18,100 / \mathrm{mm}^{3}$ and C-reactive protein of $95.6 \mathrm{mg} / \mathrm{dl}$. The hypotheses of renal colic and diverticulitis were raised.

An abdominal computed tomography with contrast was performed and showed an enlarged spleen located in the anterior pelvis with stretching and torsion of its vascular pedicle, densification of the fat adjacent to the organ, and small amount of free fluid in the pelvis. The suggested diagnosis was of a wandering spleen and torsion of its pedicle with infarction, confirmed after abdominal surgery with splenectomy and subsequent anatomopathological study (acute ischemia with intraparenchymal haemorrhage of the spleen was observed).

\section{DISCUSSION}

Wandering or ectopic spleen is a rarely diagnosed clinical entity. The nature of the illness is only recognized when complications have occurred and often diagnosed in an emergency setting. ${ }^{1}$ In adulthood, the presentations vary from splenic incidentaloma to acute abdominal emergency or chronic gastrointestinal complaints. Due to the unspecific clinical features of abdominal pain, imaging modalities play a crucial role in diagnosing ectopic spleen. ${ }^{1-3}$ Clinicians should consider wandering spleen in the differential 

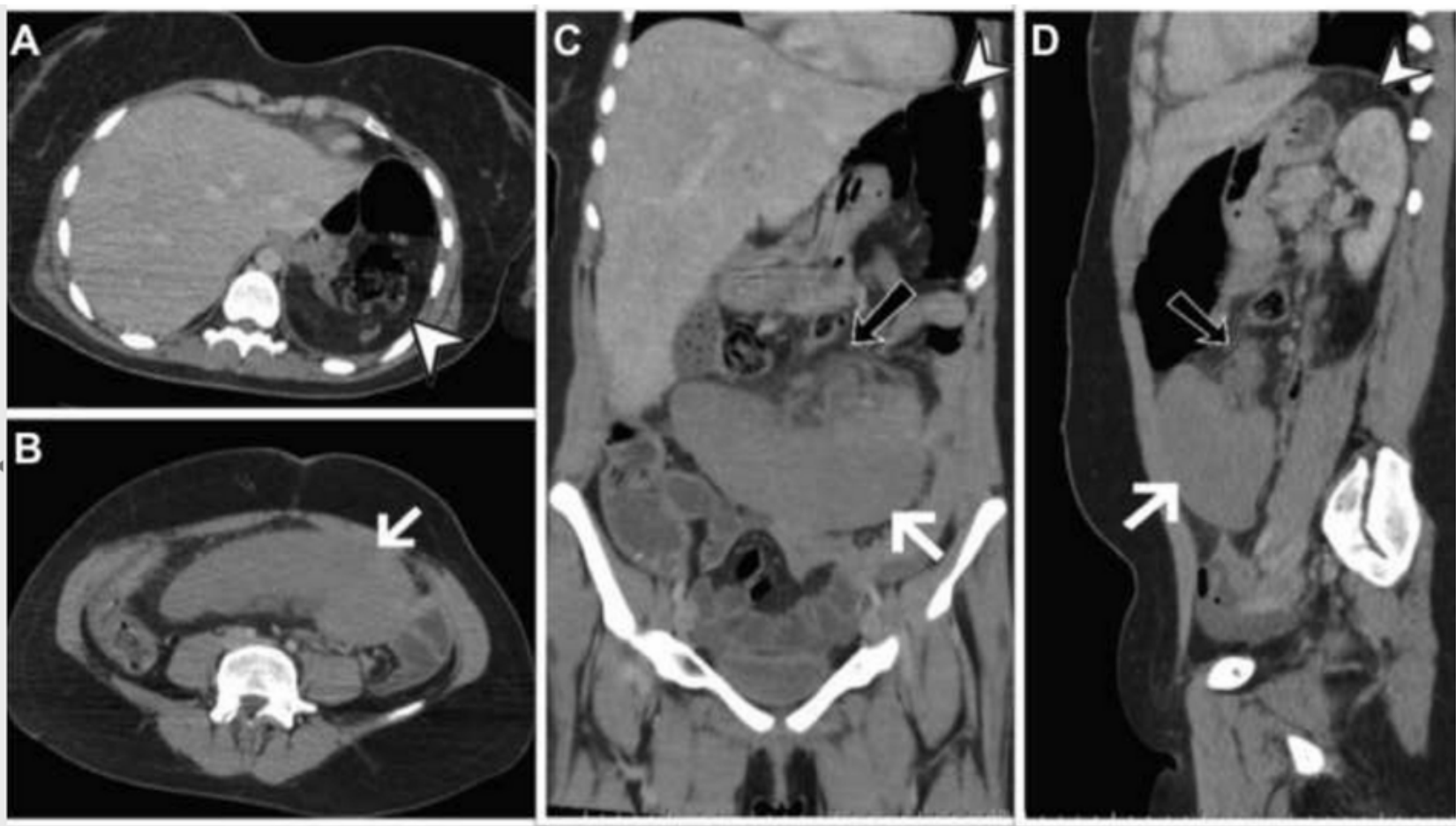

FIGURE 1 Tomographic sections in the axial plane (A and B), coronal (C) and sagittal (D), portal phase after the intravenous contrast, showing the left hypochondriac without a splenic image (head of the cursor), and the spleen being identified in the right iliac fossa (thin white arrow), of discretely increased dimensions, low contrasted, with vascular engorgement and tenuous densification of the adipose tissue with its hilum (black arrow).

diagnosis of acute abdomen. Upon diagnosis, treatment is usually surgical either splenopexy or splenectomy, depending on the degree of torsion and splenic infarction. ${ }^{1-3}$

PALAVRAS CHAVE: Baço errante. Esplenopatias. Infarto esplênico.

\section{REFERENCES}

1. Reisner DC, Burgan CM. Wandering spleen: an overview. Curr Probl Diagn Radiol. 2018;47(1):68-70.

2. Chauhan NS, Kumar S. Torsion of a wandering spleen presenting as acute abdomen. Pol J Radiol. 2016;81:110-3.

3. Carvalho CG, Vale CEP, Castro Jr PC, Frade TB. Baço migratório em hérnia paraestomal. Rev Col Bras Cir. 2008;35(5):349-50. 